\title{
DESEMPENHO E PRODUÇÃO DE LÃ DE OVELHAS LACTANTES E GANHO DE PESO E CARACTERÍSTICAS DA CARCAÇA DOS CORDEIROS ${ }^{1}$
}

\author{
PERFORMANCE AND WOOL PRODUCTION OF SHEEP AND WEIGHT \\ GAIN AND CARCASS CHARACTERISTICS OF THE LAMBS
}

\author{
Sérgio Carvalho ${ }^{2}$ Cléber Cassol Pires ${ }^{3}$ Régis Augusto Carvalho Bernardes $^{4}$ \\ Fábio Aguirre $^{5}$ Miguel Sacilotto $^{5}$ Gilberto da Rosa ${ }^{5}$
}

RESUMO

Foram estudados os efeitos da alimentação com pastagem cultivada de aveia + azevém + trevo vesiculoso ou silagem de milho + concentrado sobre o desempenho e os aspectos quantitativos da produção de lã de ovelhas de cria de parto simples ou duplo da raça Ideal, bem como o efeito destes regimes alimentares sobre o ganho de peso, as características de carcaça e os componentes do peso vivo de cordeiros alimentados ao pé da mãe. Para as variáveis estudadas das ovelhas, apenas o rendimento de lã diferiu significativamente $(P<0,01)$ entre os sistemas alimentares, sendo superior para aquelas alimentadas com silagem de milho + concentrado. Quanto ao tipo de parto, não houve diferenças significativas $(P \geq 0,05)$ para nenhuma das variáveis estudadas. Para os cordeiros, os valores obtidos de desempenho, características da carcaça e componentes do peso vivo, não diferiram significativamente $(P \geq 0,05)$ entre tratamentos.

Palavras-chave: ovinos, pastagem, pós-parto, silagem, terminação.

\section{SUMMARY}

The effect of feeding Polwarth ewes rearing singles or doubles on pasture, or on corn silage + concentrate on ewes and lambs body weigth gain ewes wool production and carcass charecteristics and body components of lambs. Only the wool yield was significantly different $(P<0.01)$ among the feedig systems, being superior for the sheep that receaving corn silage plus concentrate.There were no significant difference $(P \geq 0.05)$ for all variables between singles and doubles. For the lambs, the response of performance, carcass characteristics and live weight components were not different statistically $(P \geq 0,05)$ among treatments.

Keywords: finishing, pasture, post partumy, sheep, silage.

\section{INTRODUÇÃO}

Os cruzamentos entre raças laneiras com raças de carne têm sido muito utilizados atualmente no RS, para a produção de carne ovina (FIGUEIRÓ, 1979). Neste contexto, é importante verificar os aspectos produtivos da ovelha que, além de produzir o cordeiro, continuará a produzir lã.

Segundo SPEDDING (1966), a nutrição ao longo da lactação é um fator dominante que afeta os aspectos produtivos da ovelha. A magnitude dos efeitos da lactação sobre a produção de lã, depende em grande parte do nível nutricional ao qual os animais estão submetidos (OLIVEIRA \& FIGUEIRÓ, 1979).O crescimento de lã é influenciado pela nutrição e, em casos de carência acentuada, pode ocorrer uma interrupção (ou fraqueza) nas fibras que crescem durante este período, reduzindo o peso de velo e a qualidade da lã (OLIVEIRA \& FIGUEIRÓ, 1979; SPEDDING, 1966).

Tradicionalmente no RS, a base da alimentação dos ovinos é a pastagem natural. Nesse

${ }^{1}$ Pesquisa financiada pelo Fundo de Incentivo a Pesquisa (FIPE).

${ }^{2}$ Acadêmico de Pós-graduação em Zootecnia, Universidade Federal de Santa Maria (UFSM).

${ }^{3}$ Professor Titular, Departamento de Zootecnia, UFSM, 97105-900, Santa Maria, RS. E-mail: cpires@creta.ccr.ufsm.br. Autor para correspondência.

${ }^{4}$ Professor do Departamento de Zootecnia, UFSM.

${ }^{5}$ Aluno de graduação em Zootecnia, UFSM. 
sistema, torna-se difícil obter bons índices de produção, bem como animais jovens em condições de serem abatidos. Para tanto, é preciso modificar o meio ambiente, principalmente no que se refere à alimentação. A utilização de alimentos conservados na forma de silagem, bem como as pastagens cultivadas, são alternativas alimentares que podem ser utilizadas.

No que se refere à silagem, pouco se sabe da utilização deste alimento na nutrição de ovinos. VIEIRA (1967) relata que uma boa silagem, convenientemente usada é um dos melhores alimentos para todas as classes de ovinos, principalmente para aqueles que estão em acabamento. KOPS (1996), utilizando 50 ovelhas cruza Suffolk com cria ao pé, alimentadas por 39 dias em confinamento e recebendo silagem de milho como única alimentação volumosa, verificou $0,260 \mathrm{~kg}$ de ganho médio diário para as ovelhas e $0,372 \mathrm{~kg}$ para os cordeiros.

PILAR (1994), comparando diferentes grupos genéticos de ovinos machos castrados, confinados por um período de 80 dias, alimentados com uma dieta composta por silagem de milho $(60,5 \%$ da MS) + concentrado (39,5\% da MS) e abatidos aos 12 meses de idade, obteve uma média de ganho de peso diário de $0,146 \mathrm{~kg}$.

Outro fator a ser considerado é que durante o abate se obtém uma série de subprodutos que não fazem parte da carcaça e que afetam o rendimento. A estes, dá-se a denominação de "quinto quarto", ou seja, são todos os componentes do peso vivo, com exceção da carcaça (OSORIO, 1995). Estes componentes não vem sendo devidamente valorizados, sendo, às vezes, totalmente desprezados. Para OSORIO \& ASTIZ (1996), na comercialização de ovinos, a valorização deve ser realizada considerando o animal como um todo, remunerando além da carcaça, todos os componentes do peso vivo onde, além de vísceras comestíveis, encontra-se também a pele.

O trabalho objetivou avaliar o desempenho e a produção de lã de ovelhas com cria ao pé, da raça Ideal, submetidas a dois sistemas alimentares e o ganho de peso, características de carcaça e os componentes do peso vivo dos cordeiros submetidos a diferentes sistemas de alimentação.

\section{MATERIAL E MÉTODOS}

O trabalho foi conduzido no Setor de Ovinocultura do Departamento de Zootecnia da Universidade Federal de Santa Maria, RS, no período de 05 de junho a 29 de dezembro de 1995.Os animais foram distribuídos nos tratamentos 24 horas após a parição. 17 ovelhas (parto simples ou duplo) e respectivos cordeiros foram colocados em uma área de aproximadamente 1 ha de pastagem cultivada de aveia + azevém + trevo vesiculoso e 15 (parto simples ou duplo) foram alimentadas com silagem de milho + concentrado (milho desintegrado + farelo de soja + mistura mineral) na proporção 70:30 na matéria seca (MS), com 14\% de proteína bruta. Nesse tratamento, os animais permaneceram numa área de campo nativo $( \pm 0,4$ ha) onde recebiam no cocho a alimentação. As ovelhas foram avaliadas desde a parição até o momento da esquila (16/11/95) e os cordeiros do parto até o momento do abate, quando atingiram $\pm 30 \mathrm{~kg}$ de peso vivo. Foram realizadas pesagens no início e final do período experimental, sendo que, para um melhor acompanhamento do desempenho, foram realizadas pesagens intermediárias a cada 28 dias. Em ambos os tratamentos, não foi realizado o desmame dos cordeiros, os quais permaneceram ao pé da mãe, até o momento do abate.

As ovelhas foram esquiladas em 16 de novembro de 1995, sendo que momentos antes da esquila, foram retiradas amostras de lã de $\pm 200 \mathrm{~g}$ da região da costela para posteriores análises laboratoriais. Após a tosquia, a lã de velo e garra (patas, barriga e cabeça) foram separadas e pesadas. Para determinação do peso de velo limpo e rendimento, as amostras de lã suja foram lavadas de acordo com a técnica rotineira no laboratório de lãs da UFSM.

OS cordeiros (seis por tratamento) foram abatidos ao atingirem $\pm 30 \mathrm{~kg}$ de peso vivo, sendo coletado todo o sangue e retirados a pele, a cabeça, as patas, as vísceras e trato digestivo, que foram pesados separadamente. Em seguida, foi tomado o peso de carcaça quente e, posteriormente, as carcaças foram resfriadas em câmara frigorífica por 24 horas a uma temperatura de $2^{-} \mathrm{C}$. Após esse período, foram tomados o peso de carcaça fria, peso de quarto, peso de paleta e peso de costela.

\section{RESULTADOS E DISCUSSÃO}

As análises de variância para as variáveis estudadas mostraram não existir interação $(\mathrm{P} \geq 0,05)$ entre tipo de alimentação e tipo de parto, portanto seus efeitos foram avaliados de forma independente. Os valores de peso inicial, peso final e ganho médio diário, das ovelhas, estão expressos na Tabela 1.

Não houve diferenças $(\mathrm{P} \geq 0,05)$, tanto para tipo de alimentação como para tipo de parto, com relação as variáveis estudadas, contudo, pode-se observar que as ovelhas praticamente mantiveram peso durante a lactação. Este fato é de grande importância, pois proporciona o rápido restabelecimento orgânico da ovelha, refletindo-se positi- 


\begin{tabular}{|c|c|c|c|c|}
\hline \multirow[b]{2}{*}{ Variáveis } & \multicolumn{2}{|c|}{ Tipo de Alimentação } & \multicolumn{2}{|c|}{ Tipo de Parto } \\
\hline & Pastagem & Silagem+Conc. & Simples & Duplo \\
\hline PI (kg) & 49,10 & 42,23 & 46,29 & 45,04 \\
\hline $\mathrm{PF}(\mathrm{kg})$ & 49,37 & 45,38 & 47,93 & 46,82 \\
\hline GMD $(\mathrm{kg})$ & 0,015 & 0,036 & 0,029 & 0,018 \\
\hline
\end{tabular}

vamente no desempenho reprodutivo futuro. Conforme OLIVEIRA et al. (1995), as exigências nutricionais das ovelhas na prenhez e lactação constituem-se num importante aspecto a considerar, principalmente quando o objetivo é alta produção de carne, o que pressupõe a utilização de um manejo reprodutivo mais intenso como é o caso da obtenção de 3 partos em dois anos, para minimização da estacionalidade de oferta de cordeiros.

$\mathrm{Na}$ Tabela 2, verifica-se que não foi encontrada diferença $(\mathrm{P} \geq 0,05)$ para peso de garra, peso de velo sujo e de velo limpo, tanto no sistema alimentar como tipo de parto. O rendimento de lã foi superior $(\mathrm{P}<0,01)$ nas ovelhas alimentadas com silagem de milho + concentrado em relação as da pastagem, porém, não diferiu significativamente $(\mathrm{P} \geq 0,05)$ para tipo de parto. Os valores encontrados para rendimento, ficaram abaixo do obtido por FERRONATO \& FIGUEIRÓ (1978), que obtiveram um rendimento de $74,13 \%$ para ovelhas da raça Ideal. O maior rendimento de lã para as ovelhas

\begin{tabular}{|c|c|c|c|c|}
\hline \multirow[b]{2}{*}{ Variáveis } & \multicolumn{2}{|c|}{ Tipo de Alimentação } & \multicolumn{2}{|c|}{ Tipo de Parto } \\
\hline & Pastagem & Silagem+Conc. & Simples & Duplo \\
\hline PG (kg) & 0,33 & 0,32 & 0,35 & 0,30 \\
\hline PVS (kg) & 3,45 & 2,95 & 3,23 & 3,17 \\
\hline PVL (kg) & 2,36 & 2,15 & 2,29 & 2,23 \\
\hline $\mathrm{RD}(\%)$ & $67,55^{\mathrm{a}}$ & $73,0^{\mathrm{b}}$ & 70,7 & 69,85 \\
\hline
\end{tabular}

Médias seguidas de letras desiguais, nas linhas, diferem estatisticamente $(\mathrm{P}<0,01)$. alimentadas com silagem de milho + concentrado pode ser devido à uniformidade na qualidade do alimento oferecido e a uma menor infestação de parasitas, uma vez que a alimentação foi oferecida diariamente no cocho.

Para os valores apresentados na Tabela 3, relativos ao peso vivo inicial e final, idade ao abate, ganho de peso total e ganho médio diário, dos cordeiros, observa-se que não houve diferenças significativas $(\mathrm{P} \geq 0,05)$. Em termos de valor absoluto, notase que houve um melhor desempenho para os cordeiros alimentados com silagem, os quais tiveram $0,017 \mathrm{~kg}$ a mais de ganho médio diário e também atingiram o peso de abate 14 dias antes que os da pastagem. Isto pode ser devido ao fato de uma maior constância na qualidade do alimento fornecido no cocho, do início ao final do experimento, o que pode não ter ocorrido com a pastagem em função da influência do clima e do próprio estágio de crescimento.

Outro fator a ser considerado é que possivelmente tenha havido uma maior infestação parasitária daqueles animais alimentados exclusivamente com pastagem cultivada, uma vez que esta apresenta condições ambientais que propiciam elevadas infecções endoparasitárias. Sabe-se que os nematódeos gastrintestinais provocam, dentre outros transtornos metabólicos, redução no consumo voluntário de alimentos e prejuízos à digestão e absorção de nutrientes, que determinam redução no ganho de peso. SIQUEIRA et al (1993), comparando o ganho de peso e as infecções helmínticas de cordeiros recriados em confinamento ou em pastagem de "coast cross", observou um ganho de peso médio diário de $0,153 \mathrm{~kg}$ para os confinados e de $0,088 \mathrm{~kg}$ para os da pastagem, sendo que esta diferença foi altamente significativa $(\mathrm{P}<0,0001)$ entre tratamentos. Com relação às infecções helmínticas, verificou-se que o OPG médio dos cordeiros confinados manteve-se relativamente baixo ao longo do experimento, enquanto que os da pastagem, apresentaram um OPG médio elevado, ocorrendo, inclusive, uma mortalidade de $16,13 \%$ dos cordeiros.

Os resultados encontrados para rendimento de carcaça quente e de carcaça fria, índice de quebra ao resfriamento, percentagem de quarto, percentagem de paleta e percentagem de costela (Tabela 4) não diferiram $(\mathrm{P} \geq 0,05)$ entre tratamentos. Segundo FIGUEIRÓ (1989) e FIGUEIRÓ (1979), o cruzamento entre raças laneiras com raças de carne, bem como a disponibilidade de pastagem e o nível nutricional aportado proporcionam um maior rendimento de carne, tanto na carcaça como na porção comestível dos cortes nobres. Como no presente trabalho, foram utilizados animais oriundos do 
Tabela 3 - Valores médios ${ }^{1}$ para peso vivo inicial (PVI), peso vivo final (PVF), números de dias para abate (ND), ganho de peso total (GT) e ganho médio diário (GMD) de acordo com os tratamentos.

\begin{tabular}{lccccc}
\hline & PVI & PVF & ND & GT & GMD \\
Tratamento & $(\mathrm{kg})$ & $(\mathrm{kg})$ & $\left(\mathrm{N}^{0}\right)$ & $(\mathrm{kg})$ & $(\mathrm{kg})$ \\
& & & & & \\
\hline & & & & & \\
Pastagem & 3,75 & 31,02 & 151,5 & 27,26 & 0,182 \\
Silagem+Concentrado & 4,07 & 31,28 & 137,3 & 27,35 & 0,199 \\
Média & 3,85 & 31,11 & 146,53 & 27,29 & 0,188 \\
F & 1,14 & 0,07 & 2,54 & 0,01 & 1,03 \\
P $>$ F & 0,3034 & 0,7985 & 0,1320 & 0,9348 & 0,3278 \\
CV $(\%)$ & 14,21 & 6,46 & 11,99 & 7,04 & 16,84 \\
& & & & & \\
\hline
\end{tabular}

${ }^{1}(\mathrm{P} \geq 0,05)$.

Tabela 4 - Médias para rendimento de carcaça quente (RCQ), rendimento de carcaça fria (RCF), índice de quebra (IQ), percentagem de quarto (\% QUA), percentagem de paleta (\% PAL) e percentagem de costela (\% COST), de acordo com o tratamento.

\begin{tabular}{|c|c|c|c|c|c|c|}
\hline & RCQ & RCF & IQ & QUA & PAL & COST \\
\hline Tratamento & $(\%)$ & $(\%)$ & $(\%)$ & $(\%)$ & $(\%)$ & $(\%)$ \\
\hline Pastagem & 42,97 & 40,41 & 4,16 & 31,96 & 19,64 & 26,41 \\
\hline Silagem+Concentrado & 44,75 & 42,93 & 4,06 & 32,68 & 19,63 & 27,61 \\
\hline Média & 43,59 & 41,36 & 4,13 & 32,23 & 19,64 & 26,86 \\
\hline $\mathrm{F}$ & 1,15 & 3,53 & 0,02 & 0,50 & 0,00 & 0,36 \\
\hline$P>F$ & 0,3003 & 0,0813 & 0,8986 & 0,4899 & 0,9958 & 0,5578 \\
\hline CV $(\%)$ & 7,53 & 6,26 & 37,64 & 6,04 & 7,09 & 14,33 \\
\hline
\end{tabular}

$(\mathrm{P} \geq 0,05)$.

Tabela 5 - Médias para rendimento de carcaça quente (RCQ), percentagem de sangue $(\% \mathrm{~S})$ percentagem de pele $(\% \mathrm{P})$, percentagem de cabeça $(\% \mathrm{C})$, percentagem de patas (\%PT), percentagem de vísceras (\%VIS) e percentagem de trato digestivo (\%TD), conforme os tratamentos.

\begin{tabular}{|c|c|c|c|c|c|c|c|}
\hline & RCQ & & & & & & \\
\hline Tratamento & $(\%)$ & $\% \mathrm{~S}$ & $\% \mathrm{P}$ & $\% \mathrm{C}$ & $\% \mathrm{PT}$ & $\%$ VIS & $\% \mathrm{TD}$ \\
\hline Pastagem & 42,97 & 3,57 & 11,58 & 3,58 & 2,02 & 4,65 & 28,01 \\
\hline Silagem+Concentrado & 44,75 & 3,41 & 12,09 & 3,58 & 2,09 & 4,94 & 28,66 \\
\hline Média & 43,60 & 3,51 & 11,76 & 3,58 & 2,04 & 4,75 & 28,24 \\
\hline $\mathrm{F}$ & 1,15 & 0,63 & 0,48 & 0,00 & 1,19 & 1,62 & 0,04 \\
\hline $\mathrm{P}>\mathrm{F}$ & 0,3003 & 0,4410 & 0,5008 & 0,9694 & 0,2925 & 0,2226 & 0,8492 \\
\hline CV $(\%)$ & 7,53 & 11,09 & 12,24 & 8,43 & 6,90 & 9,66 & 23,47 \\
\hline
\end{tabular}

mesmo cruzamento (Ideal x Texel) os quais foram distribuídos ao acaso nos tratamentos, possivelmente não houve diferenças em relação às características das carcaças, por serem os animais do mesmo grupo genético. Com relação à alimentação oferecida, como procurou-se no início do experimento que a alimentação com silagem de milho + concentrado oferecesse as mesmas condições nutricionais da pastagem, este fator também não foi determinante para que houvesse diferenças em relação às variáveis das carcaças.

Os valores para rendimento de carcaça quente, rendimento de carcaça fria e percentagem de quarto foram superiores aos encontrados por ARAÚJO et al (1996), que obtiveram 39,11\%, $38,14 \%$ e $27,02 \%$, respectivamente, utilizando cordeiros $1 / 2$ Ideal $+1 / 2$ Texel abatidos com $30,9 \mathrm{~kg}$ de peso vivo, aos 177 dias de idade. Para as percentagens de quarto, paleta e costela, SILVA (1993) obteve $36,94 \%, 21,01 \%$ e $34,45 \%$ em um experimento com cordeiros Ideal x Texel abatidos aos 90 dias de idade, com peso vivo de $22,56 \mathrm{~kg}$. A discordância em relação aos resultados do presente trabalho, pode ser devido a diferenças na idade e peso de abate dos animais.

Para os componentes do peso vivo (Tabela 5), observa-se que os valores encontrados foram semelhantes e não houve diferenças $(P \geq 0,05)$ entre tratamentos.

Entre os fatores que afetam os componentes do peso vivo, estão o genótipo, sexo, idade e a variação individual do peso vivo. OSORIO et al (1996 A), comparando cinco genótipos diferentes (Merino, Ideal, Corriedale, Romney Marsh e Texel), concluíram que o genótipo apresenta um efeito sobre os componentes do peso vivo, tanto em valores absolutos como percentuais. Já OSORIO et al (1996 B), observaram que o sexo, a idade e o peso vivo ao abate são fatores que provocam uma variação nos componentes do peso vivo. 
Como no presente trabalho foram utilizados animais de mesmo genótipo e sexo, os quais foram abatidos com o mesmo peso vivo e com uma pequena diferença de idade, observa-se que o tipo de alimento oferecido, não foi determinante para que houvesse diferenças nos constituintes corporais.

\section{CONCLUSÕES}

A utilização de pastagem cultivada de aveia + azevém + trevo vesiculoso e silagem de milho + concentrado são métodos de alimentação tecnicamente viáveis para a terminação de cordeiros ao pé da mãe e não exercem influência sobre os componentes do peso vivo. Entre estes, o trato digestivo cheio e a pele são os que exercem maior influência sobre o rendimento de carcaça em ovinos. No que se refere à produção de lã, as ovelhas alimentadas com silagem de milho + concentrado apresentam melhor rendimento de lã do que aquelas da pastagem cultivada.

\section{REFERÊNCIAS BIBLIOGRÁFICAS}

ARAÚJO, J.R., PIRES, C.C., FIGUEIRÓ, P.R.P., et al. Características da carcaça e composição física do quarto de cordeiros abatidos à mesma maturidade. In: REUNIÃO ANUAL DA S.B.Z.,33, 1996. Fortaleza, CE. Anais... Ceará: SBZ, 1996. p. 256-257.

FERRONATO, O.J., FIGUEIRÓ, P.R.P. Efeito da época de parição sobre a produção de lã limpa na raça ovina Polwarth. Ciência Rural, Santa Maria, v. 8, n. 2, p. 89-85, 1978.

FIGUEIRÓ, P.R.P. Rendimento da carcaça de ovinos no Rio Grande do Sul. In: I- JORNADA TÉCNICA DE PRODUÇ̃̃O OVINA NO RS, 1979, Bagé, RS. Anais... Bagé, EMBRAPA,1979. p. 65-69.

FIGUEIRÓ, P.R.P. Carne ovina. Revista Ovinocultura, Bagé, RS, v. 15, n. 3, p. 12-13, 1989.

KOPS, M. Confinamento de ovinos. In: REUNIÃO TÉCNICA DE ZOOTECNIA - SENAR/FARSUL. Porto Alegre, RS, p. 109-123, 1996.

OLIVEIRA, N.R., MORAES, J.C.F., BORBA, M.F.S.A. Alternativas para incremento da produção ovina no sul do
Brasil. Bagé, CPPSUL-ADTT, 1995, 91 p.

OLIVEIRA, N.R., FIGUEIRÓ, P.R.P. Influência da prenhez e lactação na produção e características de lã, segundo a estação de parição. In: $1^{\underline{a}}$ JORNADA TÉCNICA DE PRODUÇÃO OVINA NO RS, 1979, Bagé, RS. Anais... Bagé, EMBRAPA,1979. p. 113-123.

OSORIO, J.C., SIERRA, I., SAÑUDO, C., et al. Componentes do peso vivo em cordeiros e borregos Polwarth e cruzas Texel $\mathrm{x}$ Polwarth. Ciência Rural, Santa Maria, v. 25, n. 1, p. 139-145, 1995.

OSORIO, J.C., ASTIZ, C.S. Qualidade da carcaça e carne ovina. In: PROGRAMA DE TREINAMENTO EM OVINOCULTURA. SENAR, Porto Alegre, RS. p. 110-190, 1996a.

OSORIO, J.C., OLIVEIRA, N.M., JARDIM, P.O., et al. Produção de carne em ovinos de cinco genótipos: 2. componentes do peso vivo. Ciência Rural, Santa Maria, v. 26, n. 3, p. 471-475, 1996 A.

OSORIO, J.C., JARDIM, P.O., PIMENTEL, M., et al. Componentes do peso vivo em cordeiros da raça Corriedale. Ciência Rural, Santa Maria, v. 26, n. 3, p. 483-487, 1996 b.

PILAR, R.C., PIRES, C.C., RESTLE, J., et al. Desempenho em confinamento e componentes do peso vivo de diferentes genótipos de ovinos abatidos aos doze meses de idade. Ciência Rural, Santa Maria, v. 24, n. 3, p. 607-612, 1994.

SILVA, C.A.S. Peso vivo ao abate e características da carcaça de cordeiros Ideal e cruzas Texel $x$ Ideal, criados em campo nativo com acesso à pastagem cultivada. Pelotas RS. 92 p. Tese (Mestrado em Zootecnia) - Universidade Federal de Pelotas, 1993.

SIQUEIRA, E.R., AMARANTE, A.F.T., FERNANDES, S. Estudo comparativo da recria de cordeiros em confinamento e pastagem. Revista Veterinária e Zootecnia, São Paulo, v. 5, p. 17-28, 1993.

SPEDDING, C.L.W. Produção ovina e o manejo do pastejo. Porto Alegre: Secretaria da Agricultura do Estado do Rio Grande do Sul, 1966. 40 p. Boletim Técnico, 3.

VIEIRA, G.N.V. Criação de Ovinos. São Paulo: Melhoramentos, 1967, cap. 4, 23, 24: Condições essenciais para a ovinocultura, alimentos e normas de alimentação: p. 53-62 e 262277.

Ciência Rural, v. 29, n. 1, 1999. 